\title{
FERRÚS ANTÓN, B. (2011). Mujer y literatura de viajes en el siglo XIX: entre España y las Américas. Valencia: Universitat de València, 124 pp. (Biblioteca Javier Coy d'estudis Nord-Americans). ISBN: 978-84-370-8106-9.
}

"Este libro pretende reflexionar sobre la literatura escrita por un grupo de viajeras latinoamericanas, norteamericanas y españolas, que recorrieron tres continentes y que dejaron constancia escrita de su periplo entre la segunda mitad del siglo XIX y principios del siglo XX" (13). La investigadora Beatriz Ferrús, especialista en estudios de género y destacadas figuras de la literatura latinoamericana como Westphalen, Flora Tristán o Dulce María Loynaz, nos presenta un sugerente libro en el que podemos escuchar la voz de varias mujeres que, desafiando el rol de su época, se lanzaron a descubrir(se) a través de diversos viajes en los que iban entretejiendo toda una red de relaciones entre mujeres intelectuales que abrazaban la ideología moderna. Profesionales y activistas que dan fe de una larga tradición de mujeres que han viajado y han escrito sobre sus viajes como lo hicieran Humboldt, Sarmiento o Martí.

Mujer y literatura de viajes en el siglo XIX: entre España y las Américas consta de cuatro capítulos: el primero, titulado "Literatura de viajes y retóricas del imperialismo" da cuenta de qué es la literatura de viajes y de su consolidación como género literario en los siglos XVIII y XIX. "Miradas a América Latina" es el segundo capítulo y el más extenso. Se centra en la mirada española a Latinoamérica de Eva Canel y Emilia Serrano (baronesa de Wilson), con cierta nostalgia del imperio perdido y un fuerte interés por la unión de los pueblos iberoamericanos. También se detiene en la perspectiva de las voces norteamericanas de Fanny Calderón de la Barca, Nellie Bly, W. L. M. Jay y Helen Sanborn en sus viajes a México y Cuba, donde percibimos el contraste entre estos países y el centro de la modernidad capitalista del que provienen estas viajeras, además de las contradicciones que viven entre los tópicos de su imaginario como extranjeras, y la realidad que experimentan. En este apartado también se incluyen las peculiares visiones de dos extranjeras que se instalan en la Patagonia y en la selva, pero en este caso son mujeres emigrantes y no viajeras. Así conocemos la vida familiar de la alemana Ella Hoffman y la entregada vida monacal de Laura de Montoya. El tercer capítulo, "Vistas desde el otro lado: La España romántica", nos muestra la otra cara de la moneda: ahora son las mujeres latinoamericanas las que viajan a España. A través de la mirada de la cubana Gertrudis Gómez de Avellaneda y la peruana Clorinda 
Matto de Turner hacemos el viaje inverso. Este apartado se complementa con la voz de la norteamericana Katherine Lee Bates y su confrontación a los tópicos del imaginario romántico sobre España. El último capítulo, "Estados Unidos: último reducto de la civilización moderna", analiza la mitología de modernidad en torno a Estados Unidos a través de la mirada de Eduarda Mansilla y Concha Espina. El ensayo se cierra con unas sucintas conclusiones que nos permiten corroborar las palabras de André Gardies cuando decía que titular es concluir, ya que nuestro viaje textual finaliza con el apartado "El mundo es uno mismo en todas partes".

Recogiendo los trabajos de Beatriz Colombi, Mary Louise Pratt, Manuel Almagro, Claire Emile Arambel-Guiñazú, Luis Carandell, Paloma Castañeda, James Clifford, Carlos Cordero, Ottmar Ette, Barbara Hodgson, Barbara Korte, Nigel Leask, Adriana Méndez Ródenas, Isabel Morant y Sol Serrano, entre otros, la investigadora Beatriz Ferrús recupera una serie de diarios y textos que casi no cuentan con bibliografía crítica previa, por lo que es encomiable su labor de recuperación textual para perfilar este nuevo territorio en la historia literaria del siglo XIX. Las viajeras que analiza suponen una ruptura en este tipo de género literario, ya que hacen visible la arbitrariedad de las categorías que se presentaban como algo natural. Estas viajeras-escritoras redefinen su identidad a través de un proceso de transculturación y de creación de un espacio colectivo de ser-mujer-intelectual en pleno proceso de (re)construcción nacional, tanto en el caso de las latinoamericanas, como en el de las norteamericanas y españolas que miran con nostalgia el imperio perdido. Beatriz Ferrús nos muestra cómo estas autoras viven una doble transformación: "En primer lugar, la de las retóricas del imperio que construyen y reconstruyen tres imaginarios: el mito de la modernidad sin límites, encarnado por los Estados Unidos; el de la barbarie, presta a ser civilizada en un nuevo acto de descubrimiento de América Latina; y el del orientalismo peninsular, donde los ecos de un pasado glorioso resuenan en un país que olvidó sumarse a la modernidad. Y en segundo lugar, la de la condición mujer, que será revisada y reescrita por los incipientes feminismos, articulados en redes transnacionales" (117).

Ferrús nos muestra cómo la asturiana Eva Canel siente las contradicciones y ambivalencias de su viaje a Latinoamérica, donde conviven de manera paradójica su ideal de patriotismo nacional y el profundo respeto que siente por el proceso de descolonización. Sus diarios recogen mitos y leyendas de las tierras visitadas junto a elementos autobiográficos, donde se percibe la nostalgia por el pasado imperial y cierta visión utópica del espacio americano, pero sobre todo, una profunda reflexión sobre la "unión iberoamericana" o "unión de los pueblos de habla española". La granadina Emilia Serrano, baronesa de Wilson, decide viajar tras enviudar y perder a su hija, iniciando un intrépido periplo por todo el continente 
americano que desembocará en Maravillas americanas y América y sus mujeres. Beatriz Ferrús destaca que la mirada de la baronesa sobre el continente es científica, pero también romántica y novelesca, donde reelabora el material legendario anteponiendo la mitología prehispánica frente a la tradición occidental. Junto a su gran amiga Eva Canel, comparte el interés por formar una red de mujeres, y de ahí el trabajo de recopilación de biografías de viajeras intelectuales "a modo de acto reivindicativo del género que se practica" (49). Uno de los objetivos marcados por las autoras analizadas en esta investigación es la deconstrucción del rol de ser mujer y los prejuicios que lo acompañan: "América y sus mujeres constituye una denuncia de cómo el Poder construye sujetos y subalternidades, de cómo genera relatos identitarios fuertes que deben volver a ser pensados" (51).

Uno de los aciertos del ensayo radica en la visión caleidoscópica que le ofrece al lector sobre las viajeras del siglo XIX. Tras mostrarnos el punto de vista de las españolas que viajan a Latinoamérica, llegan las norteamericanas, irlandesas y alemanas que viajan al sur de América. Fanny Calderón de la Barca quizás sea uno de los personajes más cosmopolitas del libro. Su educación exquisita y su visión sobre la necesidad de que las mujeres tengan un rol activo en la sociedad y la política hicieron que percibiera la transculturación como el mejor futuro posible para un mundo globalizado. Y Elizabeth Jane Cohran, mitificada bajo el pseudónimo Nelli Bly, probablemente sea uno de sus personajes más singulares. Se trata de la primera mujer dedicada profesionalmente al periodismo de investigación, a la que le impusieron el reto de dar la vuelta al mundo en menos de 80 días. A pesar de los mitos en torno a esta figura, Beatriz Ferrús desgrana las claves de un viaje que le sirve para confrontar los tópicos latinoamericanos y contemplar el mundo a través de los ojos de una estadounidense que simboliza el mito de la modernidad. También encontramos los viajes de Julia Louisa Matilda Woodruff en Cuba y de Helen Sanborn por Centroamérica como turistas, frente a Ella Hoffman y Madre Laura, que viajan para instalarse en un país extranjero sobre el que (d)escriben sus experiencias. Madre Laura es Laura de Montoya, una monja criolla que trabajó por la educación de los indios como misionera. Beatriz Ferrús sostiene que del siglo XVI al XVIII la intelectualidad femenina estaba ligada a los conventos y sus vidas al claustro, pero a finales del siglo XIX comienzan a viajar y de este modo "las monjas viajeras fueron el colectivo femenino que más escribió como grupo durante la época" (77). Entre las publicaciones más destacadas de Beatriz Ferrús encontramos diversos artículos y libros sobre la vida y obra de monjas escritoras, como Discursos cautivos: vida, escritura y convento (2004), Heredar la palabra: cuerpo y escritura de mujeres (2007) -durante el período de la América Virreinal-y La monja de Ágreda: historia y leyenda de la Dama Azul en Norteamérica (2008) -en el que 
analiza las relaciones entre los mitos de los conquistadores y los prehispánicos-. Tal y como concluye Beatriz Ferrús, estas monjas "desafiaron la imagen-mujer de la América Latina a la que llegan promoviendo un modelo de feminidad activa, donde el cuerpo pasa de objeto a herramienta" (78).

¿Cómo ven las extranjeras España? La península Ibérica del siglo XIX es la romántica, la de los toros, la andaluza y la morería, pero las intelectuales que visitan España en esa época se resisten al tópico. La cubana Gertrudis Gómez de Avellaneda, la peruana Clorinda Matto de Turner o la norteamericana Katherine Lee Bates llegan a Europa porque "el 'viejo continente' era un espacio leído, figurado por la literatura y la pintura que se quería re-conocer" (94). Clorinda de Matto se interesó especialmente por la unión entre las mujeres cultas e intelectuales a ambos lados del Atlántico igual que Emilia Serrano y Eva Canel, por lo que este viaje también se convierte en la búsqueda de una "patria de mujeres" (97). Pero las mujeres españolas y latinoamericanas también viajan a Estados Unidos, y contemplan la reciente nación como un modelo de civilización y democracia siguiendo la senda marcada por Domingo Faustino Sarmiento. La argentina Eduarda Mansilla admira a las mujeres profesionales de Norteamérica y la española Concha Espina, más que en la unión de los pueblos iberoamericanos, insiste en la necesidad de esa red de intelectuales feministas, y mira con recelo un exacerbado capitalismo que consiente la esclavitud del pueblo negro. Y a pesar de todo, en ambos textos se percibe la proyección que "Estados Unidos sobre España e Hispanoamérica ha producido, no sólo como mitología política, sino como imagen generadora de un imaginario de modernidad global" (109).

La literatura de las mujeres que recupera Beatriz Ferrús muestra sujetos que se enfrentan a la imagen femenina que la sociedad les impone, con identidades transoceánicas y transnacionales de mujeres que fueron escritoras, periodistas, intelectuales y feministas. Se trata de dietarios y cartas en los que se demuestra que "el mundo es uno mismo en todas partes, en todas partes se ama y se ríe, se padece y se llora" (20), tal y como afirma Gertrudis Gómez de Avellaneda. Se trata de un impecable ensayo que nos permite viajar a través del tiempo, de la ideología, de la construcción de la identidad nacional, de la historia y de la literatura escrita por mujeres desde los siglos pasados. 